\title{
Problems on Humanistic Care and Psychological Counseling of College Students in Rural Poverty- Stricken Areas Under COVID-19 and Countermeasures Adopted by Colleges and Universities
}

\author{
Shuqi $\mathrm{Li}^{1, *}$ \\ ${ }^{1}$ School of Architecture and Art Design, Xi'an Peihua University, Xi'an, Shaanxi 712105, China \\ *Corresponding author. Email: 11885189@qq.com
}

\begin{abstract}
The COVID-19 outbreak has forced college students to study at home for a long time. However, college students in poor rural areas are more prone to psychological issues due to learning disabilities in online courses and unfavorable family economic conditions. As a result, humanistic care and psychological counseling are needed for such students. Based on the discussion of the necessity for colleges and universities to conduct humanistic care and psychological counseling for college students in poor rural areas under the COVID-19 epidemic, this paper analyzes and discusses existing deficiencies and issues, and then puts forward corresponding countermeasures and suggestions to prevent the emergence of such issues.
\end{abstract}

\section{Keywords: rural poverty-stricken areas, college students, humanistic care, psychological counseling}

\section{INTRODUCTION}

The beginning of 2020 witnessed a sudden epidemic that hit all over the world, which significantly swayed the economy and development. Education of students at different levels is no exception. Public health emergencies and their impact on people incur negative psychological issues on different individuals a varying degree. College students, in particular, are required to attend online courses at home because of the epidemic. However, some college students in rural povertystricken areas are not well-equipped to take online courses at home: several children from one family share one mobile phone, no access or poor access to Internet in remote areas, which drags their study, resulting in serious psychological issues. In this context, the humanistic care and psychological counseling for them are highlighted.

Research on humanistic care and psychological counseling for college students in China is ample and fruitful achievements have been made. Most scholars hold that humanistic care and psychological counseling are very necessary for college students in the new era. [1] [2] The existing success of humanistic care and psychological counseling are mostly related to their strategies, applications and mechanisms for college students. [3] [4] College students in poor areas are more prone to psychological issues due to family difficulties

CLC number: G641 Document code: A and poor ability to adapt to the new environment. [5] [6] However, research on humanistic care and psychological counseling specially for college students in poor areas is rare. This paper expounds the necessity of humanistic care and psychological counseling for college students in poor rural areas in the context of COVID-19 epidemic. With this as basis, questionnaire of such students is conducted to analyze the deficiency and problems of humanistic care and psychological counseling for them. Finally, strategies of humanistic care and psychological counseling for college students in poor rural areas are proposed.

\section{THE NECESSITY OF HUMANISTIC CARE} AND PSYCHOLOGICAL COUNSELING FOR POOR RURAL COLLEGE STUDENTS UNDER THE COVID-19 EPIDEMIC

The outbreak of COVID-19 severely hit the whole economy and society. Colleges and universities across China suspended field classes and implemented online teaching, forcing college students to study online at home. College students from urban areas or with better family backgrounds are less affected given their equipment and access to online studies. The situation of such students from poverty-stricken rural areas is opposite. Some poor families enjoy no computers or smart phones to support online courses, or a sharing device for several children are real. As a result, college students in poor areas cannot study online normally. In 
addition, some remote areas do not have wired networks and can only learn through mobile networks. Such issues as poor network signal, high cost hamstring their learning, let alone staying current with learning progress, which may easily lead to excessive psychological pressure. What's worse, the COVID-19 outbreak has dragged economies across the world. Factories are shut, which indicates that poor rural families located in remote areas may experience income decline caused by unemployment, making college students at home feel the pressure of family economy and more prone to psychological issues.

Reports of students who have been unable to attend classes for months, suffer psychological problems due to excessive stress, and even commit suicide are common. Therefore, it has become an issue that needs to be solved to provide humanistic care for poor rural college students, to care about their living and learning conditions, to solve their difficulties, and to timely conduct psychological counseling for students who have already suffered serious psychological issues. This is also an important measure to consolidate poverty alleviation through education and to stabilize human capital in poor areas. In May 2020, the author distributed a total of 200 questionnaires to college students in poor areas through Sojump, a mini program in Wechat, and recovered 195. Analysis of such data shows that $75 \%$ of college students failed to study online in a timely manner because of network, equipment, etc. $65 \%$ of the samples indicated that they suffered from anxiety, worry and other psychological issues due to their inability to study normally, and even some had been under great psychological pressure. Therefore, timely humanistic care and psychological counseling for college students in poor rural areas are necessary.

\section{THE DEFICIENCY AND ISSUES OF HUMANISTIC CARE AND PSYCHOLOGICAL COUNSELING IN THE CONTEXT OF COVID-19}

Since the outbreak of the epidemic, colleges and universities has more or less carried out humanistic care and psychological counseling for students. However, desired effect is not obtained given the large number of college students, few counselors and head teachers.

\section{A. Poor humanistic care and psychological counseling in colleges and universities}

Given the current situation, colleges and universities, which should be a vital subject for humanistic care and psychological counseling for college students in poor areas, face tons of workload. Counselors and head teachers responsible for psychological counseling are rare among universities. As a result, they emphasize on statistics of students' dynamics and health over humanistic care and psychological counseling. Only 33\% of the samples felt humanistic care and psychological counseling from schools, which proves that the humanistic care and psychological counseling of college students in poor areas is seriously insufficient.

\section{B. Lack of humanistic care and psychological counseling for college students in poor areas}

During the outbreak of the epidemic, college students were unable to attend classes in schools and dispersed in communities and villages. Therefore, it is necessary for all sectors of society to pay attention to this group and provide necessary humanistic care. For example, donation of online course equipment to poor areas, and psychological counseling for college students with psychological issues. However, in practice, some institutions or enterprises that value such students enjoy limited power and little effect, especially the lack of psychological counseling. Only $21 \%$ of the samples received humanistic care and psychological counseling from local communities, enterprises and other organizations and institutions.

\section{Indifference of students and relatives on humanistic care and psychological counseling of college students in poor areas}

Due to the epidemic, college students who study at home have less communication with their classmates and relatives, and such communication are primarily conducted through Internet. Students in poor areas without Internet or equipment have fewer opportunities to communicate. Even if the convenient communication can be guaranteed, the effect is no match for that of college students living together. It is the best way to eliminate psychological issues for college students in poor areas to communicate with classmates and relatives of the same age. However, their indifference hamstrings humanistic care and psychological counseling. Only $23 \%$ of the samples showed that they had regular communication with their classmates and relatives, and were able to get some humanistic care and psychological counseling.

\section{Little effect on the humanistic care and psychological counseling of college students in poor areas}

Despite the humanistic care and psychological counseling for college students in poor areas provided by different subjects such as colleges and universities, all walks of life, classmates and friends, desired effect wasn't obtained due to low frequency, inadequate methods of psychological counseling. $64 \%$ of the samples that have received humanistic care and psychological counseling from different subjects indicated that no practical effect was achieved. 


\section{STRATEGIES OF HUMANISTIC CARE AND PSYCHOLOGICAL COUNSELING FOR COLLEGE STUDENTS IN POOR AREAS}

\section{A. Strengthening the humanistic care and psychological counseling of college students in poverty-stricken areas}

Colleges and universities still serve as the main body of humanistic care and psychological counseling for college students. It is necessary to strengthen the role of colleges and universities in humanistic care and psychological counseling, especially for college students in poor areas. Full-time counselors and head teachers should be appropriately increased to grasp the actual situation of college students in poor areas, and timely relieve students' psychological issues. In addition, psychological counseling departments in colleges and universities should also be fully utilized to carry out targeted psychological counseling for college students in poor areas with psychological issues. Colleges and universities that have not yet opened their new term should conduct psychological counseling through telephone, Internet and etc., and those that have opened should relieve the psychological pressure of college students in poor areas through face-to-face communication.

\section{B. Encouraging all sectors of society to offer humanistic care and psychological counseling to college students in poor areas through multiple channels}

Colleges and universities alone cannot shoulder humanistic care and psychological counseling for college students in poor areas. Therefore, it is a must to mobilize and encourage the participation of all sectors of society, such as communities and village institutions, which are supposed to heed the actual living and learning situation of college students from poor families and offer them a hand during difficult time. Powerful enterprises and institutions should be mobilized to donate equipment for online course, so that college students in poor areas can feel the love of all walks of life, set up hope and relieve psychological pressure.

\section{Enhancing the classmates' and friends' attention of humanistic care and psychological counseling for college students in poor areas}

Classmates, relatives and friends are the groups that have the closest relationship with college students. Students of the same age share hobbies. Their humanistic care and psychological counseling is of great importance to relieve the psychological pressure of college students in poor areas. The communication should be strengthened, mutual help is essential in study and other aspects to ease their academic worries. Relatives and friends should pay close attention to the psychological state of college students in poor areas and provide necessary guidance and help under high psychological pressure.

\section{Scientific care and psychological counseling should be adopted to improve effect}

Scientific approach should be adopted in humanistic care and psychological counseling for college students in poor areas to improve the practical effect. Colleges and universities should make efforts and invite professionals of psychology and other related majors to communicate with college students in poor areas with psychological issues. Other subjects involved should also adopt appropriate humanistic care and easy communication to resolve their psychological barriers.

\section{CONCLUSION}

As college students in rural poverty-stricken areas are more prone to psychological issues due to COVID19 outbreak, attention from colleges and societies is required. Humanistic care and scientific psychological counseling help to relieve psychological issues, so that they can finish learning task, and maintain a healthy and positive attitude. Competent human capital in poor areas are also guaranteed.

\section{References}

[1] Liang Bo, Wang Ziqi, Zhou Xue, et al. Research on the necessity of integrating humanistic care into the ideological and political education of college students [J]. Rural Education, 2020(6): 1. (in Chinese)

[2] Luo Hefei. Discuss the problems and effective countermeasures of college students' psychological counseling [J]. Psychology Monthly, 2020,15(2):53. (in Chinese)

[3] Li Shuqi. Research on countermeasures of Humanistic Care and Psychological Counseling in ideological and Political Education of College Students in the New Era [J]. Hubei Agricultural Mechanization, 2019(14):49-50. (in Chinese)

[4] Li Shuqi. Research on Humanistic Care and Psychological Counseling in Ideological and Political Education in Shaanx Private Colleges [J]. Rural Economy and Science-Technology, 2017,28(8):314-315. (in Chinese)

[5] Ge Bin. Analysis of psychological counseling and self-help improvement of poor college students [J]. Modern Communication, 2019(15):32, 31. (in Chinese)

[6] Pan Min. On Humanistic Care in Ideological and Political Education of Poor College Students [J]. Knowledge Economy, 2018(23):139, 141. (in Chinese) 